\title{
Chronic Interleukin-6 Alters NMDA Receptor-Mediated Membrane Responses and Enhances Neurotoxicity in Developing CNS Neurons
}

\author{
Zhihua Qiu, Dan D. Sweeney, Jeffrey G. Netzeband, and Donna L. Gruol \\ Department of Neuropharmacology and AIDS Research Center, The Scripps Research Institute, La Jolla, California 92037
}

Recent studies show that the cytokine interleukin-6 (IL-6) is expressed at elevated levels in the CNS in several disease states and contributes to the neuropathological process. The mechanisms through which IL-6 exerts its CNS effects are primarily unknown. We have investigated the pathophysiological effects of IL-6 on developing CNS neurons using a culture model system and a chronic treatment paradigm. Here, we show, using current- and voltage-clamp recordings, that chronic IL-6 treatment of developing cerebellar granule neurons increases the membrane and current response to NMDA and that these effects are the primary mechanism through which IL-6 produces an enhanced calcium signal to NMDA. We also show that calcium influx through voltage-sensitive calcium channels contributes to the enhanced calcium signal to NMDA in the IL-6-treated neurons in a developmentally regulated man-

Cytokines, including interleukin-6 (IL-6), are thought to play both physiological and pathological roles in the CNS (Lipton and Kater, 1989; Hopkins and Rothwell, 1995; Gruol and Nelson, 1997). Under normal physiological conditions, IL-6 levels in the CNS are low. However, elevated levels of IL-6 occur in many CNS diseases, including human immunodeficiency virus (HIV) infection (Laurenzi et al., 1990; Gallo et al., 1991; Perrella et al., 1992; Tyor et al., 1992), Alzheimer's disease (Blum-Degen et al., 1995), autoimmune disease (Hirohata and Miyamoto, 1990), and meningitis caused by bacterial (Waage et al., 1989) or viral (Frei et al., 1989) infection. Consistent with a role of IL- 6 in pathological processes, elevated levels of IL-6 mRNA and protein occur in the CNS of animal models of neurodegenerative diseases (Gijbels et al., 1990; Grau et al., 1990; Minami et al., 1991). Moreover, prominent neurodegeneration is observed in the CNS of transgenic mice that chronically overexpress IL-6 in the CNS (Campbell et al., 1993). CNS microglia and astrocytes in vitro produce large quantities of IL-6 when stimulated (Lee et al., 1993) and are thought to be important sources of IL-6 in CNS disease. CNS neurons in vivo are closely associated with microglia and astrocytes and are likely to be exposed to the high concentrations of glial-derived IL-6 under pathological conditions.

\footnotetext{
Received April 7, 1998; revised Sept. 10, 1998; accepted Oct. 7, 1998.

This work was supported by National Institute of Mental Health Grants MH47680 and National Institute of Drug Abuse Grant DA10187. We thank Pfizer, Inc. for the gift of $\omega$-agatoxin IV-A, Shannon Conroy for technical assistance, Jaimes Schneelock for performing some of the experiments, and Floriska Chizer for secretarial help.

Correspondence should be addressed to Dr. Donna L. Gruol, Department of Neuropharmacology CVN11, The Scripps Research Institute, 10550 North Torrey Pines Road, La Jolla, CA 92037.

Copyright (C) 1998 Society for Neuroscience $\quad 0270-6474 / 98 / 1810445-12 \$ 05.00 / 0$
}

ner and that the membrane depolarization to NMDA is more sensitive to the NMDA receptor antagonist ifenprodil in the IL-6-treated neurons compared with control neurons at a late developmental stage, consistent with a larger proportion of NMDA receptors containing the NMDAR2B subunit in the IL-6treated neurons. Additional studies show that IL-6 treatment reduces the number of granule neurons in culture and enhances neurotoxicity involving NMDA receptors. These results support a pathological role for IL- 6 in the CNS and indicate that NMDA receptor-mediated functions are likely to play a critical role in neuropathological changes observed in CNS diseases associated with elevated CNS levels of IL-6.

Key words: cytokine; interleukin-6; NMDA receptors; CNS neurons; intracellular calcium; development; neurotoxicity

The mechanisms through which IL-6 affects neurons in disease are only beginning to be understood. CNS neurons from both immature and adult animals express IL-6 receptor (IL-6R) mRNA (Schobitz et al., 1993; Gadient and Otten, 1994), although the functional role of IL-6Rs in CNS neurons remains to be elucidated. The IL-6R shares an intracellular transduction subunit (i.e., gp 130) and biochemical pathways with neuronal growth factor receptors, such as ciliary neurotrophic factor and leukemia inhibitory factor (Ip et al., 1992; Stahl et al., 1994), and may influence the CNS by regulating pathways normally used during neuronal development. The availability of a well characterized in vitro developmental model of CNS neurons known to express IL-6R mRNA, cerebellar granule neurons (Schobitz et al., 1993), and the technical advantages of a culture preparation have led us to use this model to investigate the pathophysiological effects of IL-6 on CNS neurons.

We showed previously that chronic IL-6 treatment of granule neurons developing in culture enhances NMDA receptormediated intracellular calcium signals and increases resting calcium levels (Holliday et al., 1995; Qiu et al., 1995). These results implicate NMDA receptors and intracellular calcium as important mechanisms through which IL-6 alters neuronal function. In the current study, we show that the primary mechanism underlying the effects of IL-6 on NMDA receptormediated calcium signals in the granule neurons is an enhancement of the membrane and current response to NMDA. We show also that neurons subjected to chronic IL-6 treatment exhibit altered sensitivity to the NMDA receptor antagonist ifenprodil and increased sensitivity to NMDA receptormediated neurotoxicity. 


\section{MATERIALS AND METHODS}

Cell culture. Cerebellar granule neuron cultures were prepared from 8-d-old postnatal rats (Sprague Dawley; Charles River Laboratories, Wilmington, MA) by a standard enzyme treatment protocol as described previously (Qiu et al., 1995). Briefly, cerebella were dissociated in calcium-free saline with trypsin and DNase and plated on MATRIGELcoated (Collaborative Biomedical Products, Bedford, MA) cover glasses $\left(10^{6}\right.$ cell/35 mm culture dish). The neurons were grown in DMEM-F-12 (Life Technologies, Gaithersburg, MD) plus $10 \%$ horse serum (heatinactivated) supplemented with $30 \mathrm{~mm}$ glucose, $2 \mathrm{~mm}$ glutamine, $20 \mathrm{~mm}$ $\mathrm{KCl}$, and penicillin $(20 \mathrm{U} / \mathrm{ml})-$ streptomycin $(20 \mu \mathrm{g} / \mathrm{ml})$. Medium $(0.5 \mathrm{ml})$ without serum was added every $7 \mathrm{~d}$. Treatment with 5-fluoro-2'deoxyuridine $(20 \mu \mathrm{g} / \mathrm{ml})$ on the first and fourth days after plating minimized the number of contaminating astrocytes.

Human recombinant IL-6 (Boehringer Mannheim, Indianapolis, IN) was dissolved in physiological saline at $100,000 \mathrm{U} / \mathrm{ml}$ as a stock solution and stored at $-20^{\circ} \mathrm{C}$. IL- 6 at a concentration of $5 \mathrm{ng} / \mathrm{ml}(500 \mathrm{U} / \mathrm{ml})$ was added to the granule neuron cultures at $1,4,7$, and $11 \mathrm{~d}$ in vitro (DIV). Sister cultures that received no IL-6 treatment were used for controls. For all experiments, the IL-6-containing medium was replaced with saline without IL-6 before measurements were made.

Electrophysiology. Current- and voltage-clamp recordings were made from the somatic region of the granule neurons using the nystatin perforated-patch technique, the Axopatch patch-1C amplifier (Axon Instruments, Foster City, CA), and pCLAMP software (Axon Instruments) following standard methods (Gruol and Parsons, 1994; Netzeband et al., 1997). For current-clamp recordings, the electrode solution contained: $6 \mathrm{mM} \mathrm{NaCl}, 154 \mathrm{mM} \mathrm{K}^{+}$gluconate, $2 \mathrm{mM} \mathrm{MgCl}_{2}, 10 \mathrm{~mm}$ glucose, $1 \mathrm{~mm}$ BAPTA, $0.5 \mathrm{~mm} \mathrm{CaCl}_{2}, 10 \mathrm{~mm}$ HEPES-KOH, pH 7.3, and $200 \mu \mathrm{g} / \mathrm{ml}$ nystatin. Nystatin-free saline was used to fill the tip of the patch electrode. For voltage-clamp recordings, $\mathrm{Cs}^{+}$gluconate $(154 \mathrm{~mm})$ was substituted for $\mathrm{K}^{+}$gluconate. The bath saline for both current- and voltage-clamp experiments was physiological saline or $\mathrm{Mg}^{2+}$-free physiological saline with $5 \mu \mathrm{M}$ glycine. The composition of the physiological saline was (in mM): $140 \mathrm{NaCl}, 3.5 \mathrm{KCl}, 0.4 \mathrm{KH}_{2} \mathrm{PO}_{4}, 0.33 \mathrm{Na}_{2} \mathrm{HPO}_{4}, 2$ $\mathrm{MgSO}_{4}, 2.2 \mathrm{CaCl}_{2}, 10$ glucose, and $10 \mathrm{HEPES}-\mathrm{NaOH}, \mathrm{pH} 7.3$. In one series of voltage-clamp experiments, the extracellular calcium level was increased. For these experiments, the bath contained high calcium saline of the following composition (in $\mathrm{mm}$ ): $100 \mathrm{NaCl}, 2.5 \mathrm{KCl}, 30 \mathrm{CaCl}_{2}, 10$ glucose, and $10 \mathrm{HEPES}-\mathrm{NaOH}, \mathrm{pH}$ 7.3. The electrode solution contained: $140 \mathrm{mM} \mathrm{CsCl}_{2}, 2 \mathrm{~mm} \mathrm{MgCl}_{2}, 10 \mathrm{~mm}$ glucose, $1.1 \mathrm{~mm}$ EGTA, 10 $\mathrm{mM} \mathrm{HEPES}-\mathrm{KOH}, \mathrm{pH} 7.3$, and $200 \mu \mathrm{g} / \mathrm{ml}$ nystatin and sucrose to adjust the osmolarity to 310 mOsm. Nystatin-free saline of the same composition was used to fill the tip of the patch electrode. All experiments were performed at room temperature $\left(\sim 23^{\circ} \mathrm{C}\right)$.

Drug application. Cells were stimulated with NMDA (0.02-1 mM; Tocris Cookson, Ballwin, MO), a selective agonist at the NMDA subtype of glutamate receptors, or $\mathrm{K}^{+}\left(150 \mathrm{~mm}\right.$ or $25 \mathrm{mM}$; $\mathrm{K}^{+}$substituted for $\mathrm{Na}^{+}$in physiological saline), a depolarizing agent. For studies with NMDA, the cell bath and agonist solutions were $\mathrm{Mg}^{2+}$-free physiological saline containing $5 \mu \mathrm{M}$ glycine. For studies of $\mathrm{K}^{+}$depolarization, the bath contained normal physiological saline. NMDA or $\mathrm{K}^{+}$was applied by a brief (1 sec) microperf usion pulse from a drug micropipette (1-3 $\mu \mathrm{m}$ tip diameter) placed near the target neurons. NMDA at $200 \mu \mathrm{M}$ was used in most experiments and produced an easily quantifiable response in both calcium imaging and electrophysiological experiments. A dye (fast green, $0.05 \mathrm{mg} \%$ ) was included in the agonist solution to monitor neuronal exposure. The dye had no effect by itself nor did it influence the response to NMDA or $\mathrm{K}^{+}$. The time course of dye exposure indicated that the onset of neuronal exposure to the stimulant was relatively fast, occurring during the initial phase of the 1 sec application period, whereas the clearance of the dye from the neuron (by diffusion) was relatively slow, taking $\sim 5-10 \mathrm{sec}$ for visual clearance. Bath saline was exchanged between stimulations. NMDA was stored as a stock solution at $50 \mathrm{mM}$ and dissolved in bath saline the day of the experiment.

Bath application of the NMDA receptor antagonists D(-)-2-amino-5phosphonopentanoic acid (D-AP-5) (50 $\mu \mathrm{M}$; Tocris Cookson) or ifenprodil (0.5 $\mu \mathrm{M}$; Sigma, St. Louis, MO) was used in some studies. These antagonists were dissolved in bath saline. Voltage-sensitive calcium channel (VSCC) blockers were also tested by bath application, including $5 \mu \mathrm{M}$ nimodipine to block L-type channels, $1 \mu \mathrm{M} \omega$-conotoxin GVIA to block $\mathrm{N}$-type channels, and $200 \mathrm{nM} \omega$-agatoxin IV-A to block P- and Q-type channels (referred to as P/Q-type). Stock solutions of nimodipine (20 $\mathrm{mM}$; Sigma) were prepared in dimethyl sulfoxide (DMSO). The final concentration of DMSO was $0.025 \%$ in the cell bath solution at the final concentration of nimodipine. In control experiments, DMSO had no effects by itself. $\omega$-Agatoxin IV-A was a gift from Pfizer (Gorton, CT), and $\omega$-conotoxin GVIA was purchased from Peptides International (Louisville, KY); both were dissolved in bath saline.

Intracellular calcium measurement. Intracellular calcium was determined for individual cells using standard microscopic fura-2 digital imaging (Grynkiewicz et al., 1985) and previously published methods (Qiu et al., 1995). Granule neurons were loaded with $1.5 \mu \mathrm{M}$ fura-2 AM and $0.02 \%$ pluronic F-127 (Molecular Probes, Eugene, OR) in physiological saline for $30 \mathrm{~min}$. For experiments, the cover glass was mounted in a chamber attached to the imaging microscope. The recording chamber contained physiological saline (see above). Live video images were recorded with a SIT-66 video camera (DAGE-MTI, Michigan City, IN) and digitized by computer. Real-time digitized display, image acquisition, and calcium measurements were made with microcomputer imaging device (MCID) imaging software (Imaging Research, St. Catharines, Ontario). Intracellular calcium levels were estimated by converting fluorescence ratios $(340 \mathrm{~nm} / 380 \mathrm{~nm})$ to intracellular calcium concentrations using the following formula: [calcium $]_{\mathrm{i}}=K_{\mathrm{d}}\left(R-R_{\min }\right) /\left(R_{\max }-R\right) *$ $F_{\mathrm{o}} / F_{\mathrm{s}}$, where $R$ is the ratio value, $R_{\min }$ is the ratio for a calcium free solution, $R_{\max }$ is the ratio for a saturated calcium solution, $K_{\mathrm{d}}$ is 135 (the dissociation constant for fura-2), $F_{\mathrm{o}}$ is the intensity of a calcium free solution at $380 \mathrm{~nm}$, and $F_{\mathrm{s}}$ is the intensity of a saturated calcium solution at $380 \mathrm{~nm}$. The low level of background fluorescence eliminated the need for background subtraction. Calibration was done using fura salt (100 $\mu \mathrm{M})$ in solutions of known calcium concentration (Molecular Probes kit C-3009). All experiments were performed at room temperature $\left(\sim 23^{\circ} \mathrm{C}\right)$.

Data analysis. Calcium signals, membrane depolarizations, and current responses to NMDA were quantified by measurement of the peak amplitude relative to baseline or resting levels. The relatively slow system used for agonist application precluded a meaningful assessment of response kinetics. For calcium imaging studies, two or three cultures for each treatment group (control and IL-6) were examined per experiment. For each culture, 5-15 granule neuronal somata were measured in each microscopic field, and at least two microscopic fields were measured in each culture. For electrophysiological studies, one control and one IL-6 culture were examined per experiment. Electrophysiological recordings were made from one to five neurons in each culture, depending on the experimental protocol. Data from several cultures and culture sets were pooled for statistical analyses. Values are expressed as mean \pm SEM. Statistical significance $(p<0.05)$ was determined by two-way ANOVA, followed by the Fisher post hoc test for multiple comparisons.

Neurotoxicity assay. Neurotoxicity was assessed using a standard lactate dehydrogenase (LDH) assay (Murphy et al., 1993; Johnson, 1995) and measurement of cell cluster size. LDH release was determined with a commercial LDH kit (Boehringer Mannheim). For studies involving NMDA toxicity, delayed toxicity was assessed (Koh and Choi, 1987). The protocol was as follows. The growth media was removed, and the cells were challenged with NMDA dissolved in $\mathrm{Mg}^{2+}$-free physiological saline containing $5 \mu \mathrm{M}$ glycine for $10-15 \mathrm{~min}$. The NMDA solution was replaced with serum-free culture media (DMEM-F-12 without phenol red), and the cultures were returned to the incubator. On the next day (18-24 hr), delayed toxicity was assessed by spectrophotometric measurement of LDH levels in the culture media.

Neuronal cluster size was used as an index of cell survival. We showed previously that during their development in culture the majority of granule neurons in control and IL-6-treated cultures migrate and form clusters connected by fiber tracts (Qiu et al., 1995). The size of the clusters correlates with the cell survival as measured by the 3-[4,5dimethylthiazol-2yl]-2,5-diphenyltetrazolium bromide tetrazolium salt assay (Ankarcrona et al., 1995; Johnson, 1995) for viable neurons (data not shown) and thus can be used as a relative measure of cell number. The area of the cell clusters was measured in fixed preparations of control and IL-6-treated cultures using MCID imaging software (Imaging Research).

\section{RESULTS}

\section{IL-6 enhances the membrane depolarization to NMDA in cerebellar granule neurons}

Parallel electrophysiological and calcium imaging experiments showed that brief $(1 \mathrm{sec})$ application of NMDA $(200 \mu \mathrm{M})$ to cultured granule neurons elicits both a membrane depolarization and an intracellular calcium signal (Fig. 1). Bath application of 
A

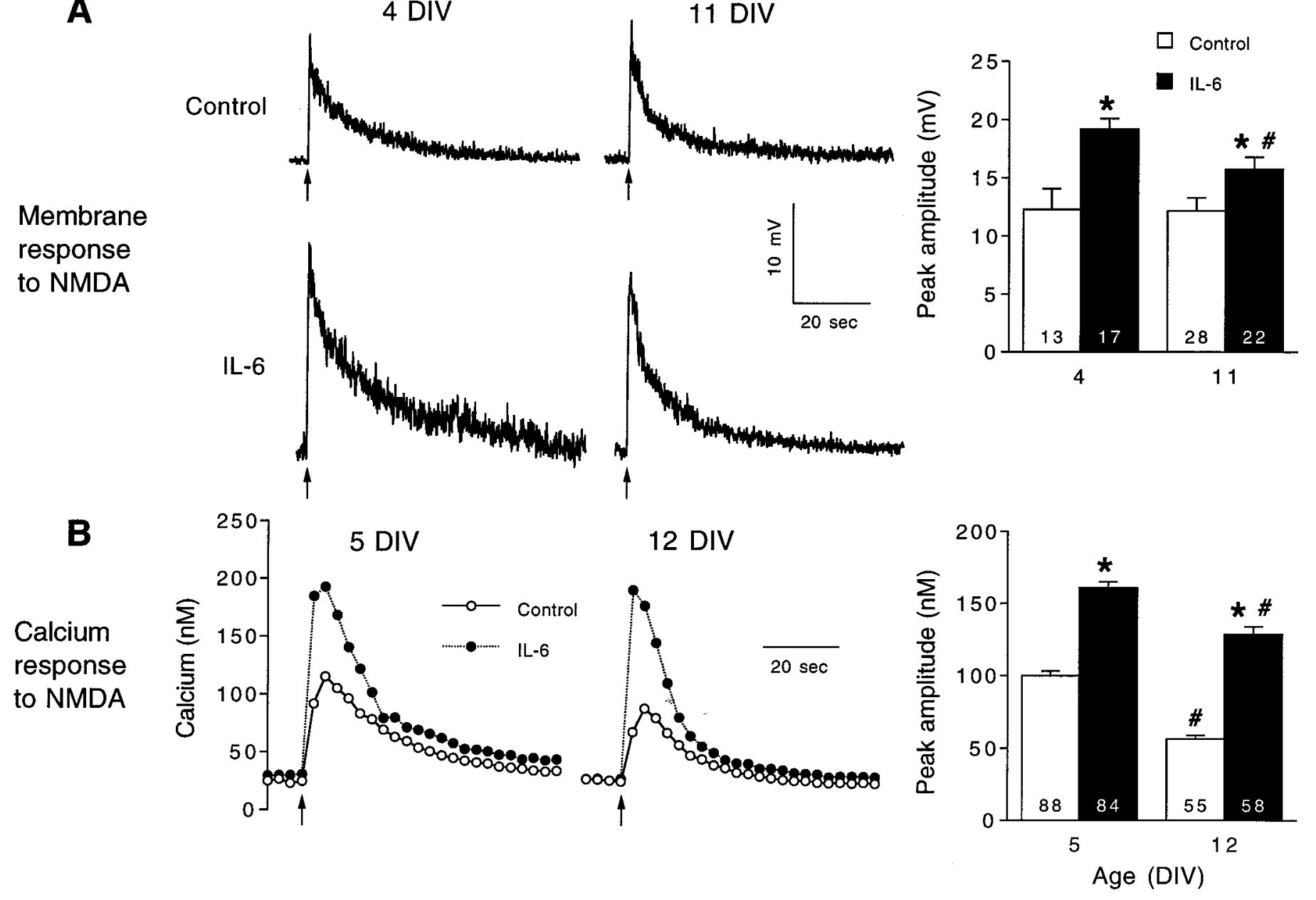

Figure 1. IL-6 enhances the membrane depolarization and intracellular calcium signal to NMDA in cerebellar granule neurons. $A$, Representative current-clamp (perforated-patch method) recordings of the membrane depolarization to NMDA in control and IL-6-treated neurons at two developmental stages, 4 and 11 DIV. NMDA $(200 \mu \mathrm{M})$ was applied at the arrows from a micropipette by brief $(1 \mathrm{sec})$ microperfusion. Mean \pm SEM values for the peak amplitude of the membrane depolarization at the two developmental stages studied are shown in the graph at the right. $B$, Representative recordings of the intracellular calcium signals evoked by application of NMDA in control and IL-6-treated neurons at two developmental stages, 5 and 12 DIV. NMDA was applied as in the electrophysiological studies. Mean \pm SEM values for the peak amplitude (relative to resting levels) of the intracellular calcium signals at the two developmental stages studied are shown in the graph at the right. Significant differences $(p<0.05)$ between control and IL-6-treated neurons are indicated by asterisks. Significant $(p<0.05)$ age-dependent differences within the same treatment group are indicated by number signs. Numbers in the bars represent the number of cells studied.

the competitive NMDA receptor antagonist D-AP-5 $(50 \mu \mathrm{M})$ blocked both responses in control and IL-6-treated neurons (data not shown), indicating that the membrane depolarization and intracellular calcium signal produced by NMDA were induced specifically by NMDA receptor activation.

The membrane depolarization and intracellular calcium signal to NMDA were affected similarly by IL-6 treatment during granule neuron development. The experiments were performed at two culture ages, 4-5 and 11-12 DIV, reflecting early and late developmental stages. Chronic IL-6 treatment starting at 1 DIV enhanced significantly the membrane depolarization and intracellular calcium signal to NMDA at both developmental stages (Fig. 1). The parallel effect of IL-6 on these responses suggests that common mechanisms underlie both effects. For example, the increased intracellular calcium signal to NMDA in IL-6-treated neurons could result from the larger membrane depolarization to NMDA and consequently greater calcium influx through NMDA receptor-gated channels or VSCCs activated by the membrane depolarization. Several types of experiments were performed to identify the mechanisms mediating the effects of IL-6 on NMDAstimulated responses in the granule neurons.

\section{Effects of IL-6 on membrane properties}

Several mechanisms could produce the larger membrane depolarization to NMDA in the IL-6-treated neurons. For example, an increase in input resistance or resting membrane potential in the IL-6-treated neurons would result in a larger membrane depolarization to NMDA. However, examination of these properties under current clamp in control and IL-6-treated neurons showed that IL-6 treatment produced only minor changes in input resistance and resting membrane potential. Moreover, the changes in input resistance and resting membrane potential were not consistent across developmental stages, in contrast to the effect of IL-6 treatment on the membrane depolarization and intracellular calcium signal to NMDA, which were increased at both developmental stages. Results are summarized in Figure 2. Input resistance (determined from the slope of the currentvoltage curves) in the hyperpolarizing range of potentials was 
A. Input Resistance: Hyperpolarizing

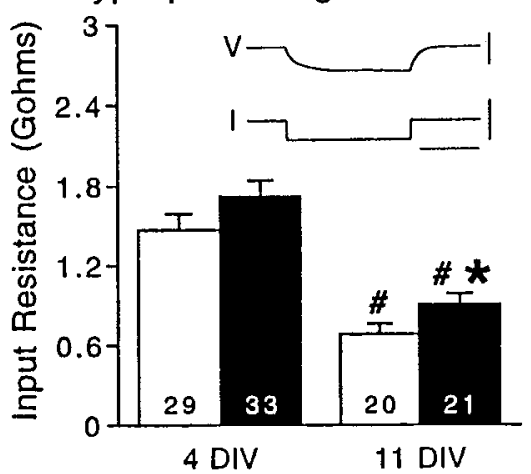

B. Input Resistance: Depolarizing

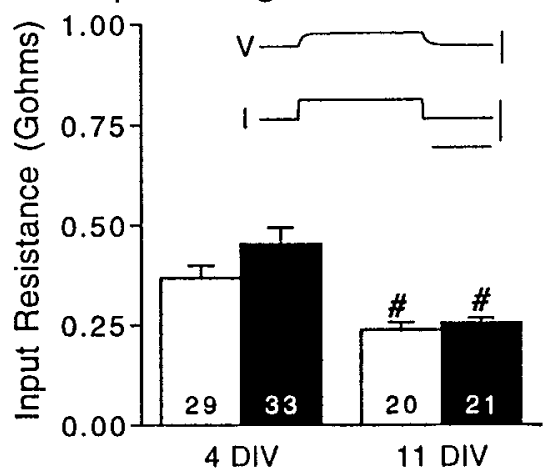

C. Resting Membrane Potential (mV) 4 DIV

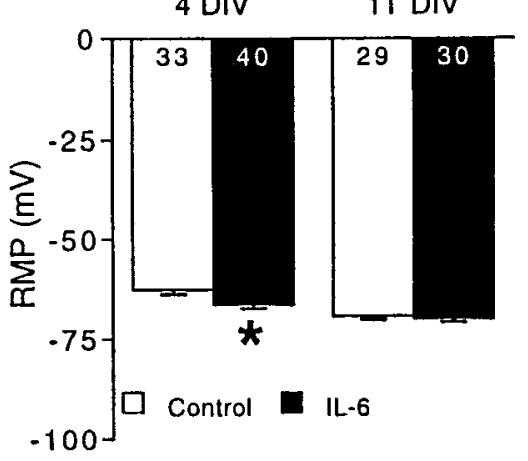

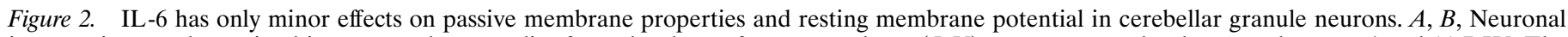

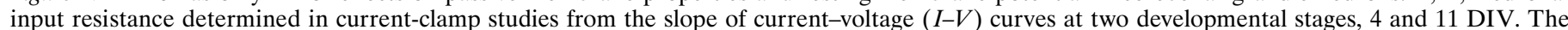

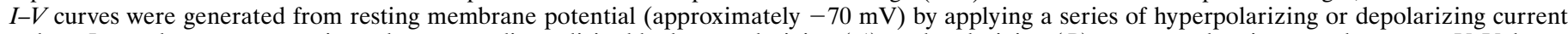

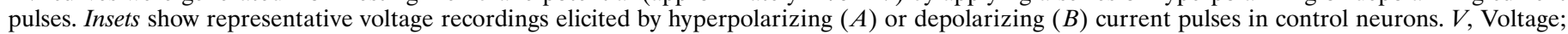

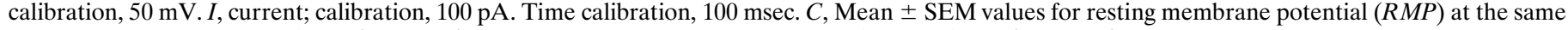

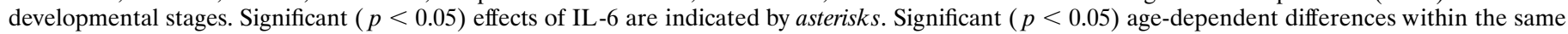
treatment group are indicated by number signs. Numbers in the bars indicate the number of cells studied.

significantly larger in the IL-6-treated neurons compared with control neurons at $11 \mathrm{DIV}$; there was no significant difference at 4 DIV (Fig. 2A). Input resistance in the depolarizing range of potentials was similar in control and IL-6-treated neurons at both developmental stages (Fig. 2B). Both control and IL-6-treated neurons showed a similar developmental decline in the depolarizing and hyperpolarizing input resistance. Resting membrane potential was slightly more negative in the IL-6-treated neurons compared with control neurons at 4 DIV; there was no significant difference at 11 DIV (Fig. 2C). Thus, effects of IL-6 on input resistance and resting membrane potential may contribute to differences in the magnitude of the membrane depolarization to NMDA between control and IL-6-treated neurons, but these effects are unlikely to be the primary mechanism responsible for the enhanced membrane depolarization to NMDA in the IL-6treated neurons.

\section{IL-6 enhances the current response to NMDA in cerebellar granule neurons}

The larger membrane depolarization to NMDA in the IL-6treated granule neurons could also result from an increase in NMDA receptor number in the cell membrane or an alteration in the functional properties of the receptors. As a first step toward determining whether IL-6 affects these properties, we measured several characteristics of the current response to NMDA in control and IL-6-treated neurons under voltage clamp. Figure 3 shows representative voltage-clamp recordings of the current responses to NMDA at two holding potentials in a 4 DIV granule neuron (Fig. $3 A$ ) and current-voltage curves showing mean values for the current response to NMDA at different holding potentials in 4 and 11 DIV granule neurons (Fig. 3B). NMDA current amplitudes were larger at 11 DIV compared with 4 DIV for both control and IL-6-treated neurons, consistent with a developmental increase in NMDA receptor number and/or a change in receptor properties during development. IL-6 treatment enhanced the peak amplitude of the current response to NMDA at all holding potentials at both developmental stages. Significant differences were observed at holding potentials of $-70 \mathrm{mV}$, the approximate resting potential of the granule neurons, and +50
$\mathrm{mV}$ at both developmental stages. These results indicate that the larger membrane depolarization to NMDA in the IL-6-treated neurons results from a larger current response to NMDA.

An increased current response to NMDA in the IL-6 treated neurons would be expected to result in greater calcium influx through NMDA receptor channels and consequently a larger calcium signal to NMDA unless there was a compensatory change in the functional properties of the NMDA receptor channels. One functional property that could affect calcium influx is the relative permeability of the NMDA receptor channel to calcium. To determine whether IL-6 treatment affected this property, we measured the reversal potential for the current response to NMDA under voltage clamp in control and IL-6-treated neurons. Reversal potential measurements were made under two conditions: (1) with physiological levels of calcium in the bath $\left(\mathrm{Mg}^{2+}\right.$ free physiological saline with $5 \mu \mathrm{M}$ glycine) or (2) with the bath saline containing elevated calcium, a condition that would facilitate identification of an IL-6-induced change in the calcium permeability of the NMDA receptor channel. When the bath contained physiological levels of calcium, the reversal potential for the current response to NMDA was $\sim 10 \mathrm{mV}$ in both control and IL-6-treated neurons (Fig. 3B), consistent with values reported by others for NMDA receptor-mediated currents in cerebellar granule neurons (Traynelis and Cull-Candy, 1991) and suggesting that the ion selectivity of the receptor channel was not altered dramatically by IL- 6 treatment. When the bath contained elevated extracellular calcium ( $30 \mathrm{~mm}$; extracellular sodium was reduced accordingly; see Materials and Methods), the reversal potential for the current response to NMDA (pooled data from 6 , 8 , and 12 DIV neurons) was $18 \pm 1 \mathrm{mV}$ for both control $(n=10)$ and IL-6-treated $(n=9)$ neurons, further indicating that IL-6 treatment did not alter the calcium permeability of the NMDA receptor channel.

NMDA receptors show differential pharmacological and functional properties, depending on their subunit composition (McBain and Mayer, 1994). For example, low micromolar concentrations of the drug ifenprodil act selectively to block receptors containing the NMDAR2B subunit (Williams, 1993; Priestly 
A

Control

IL-6

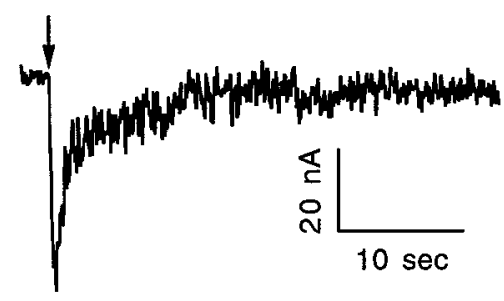

$\mathrm{Vh}=-70 \mathrm{mV}$

NMDA

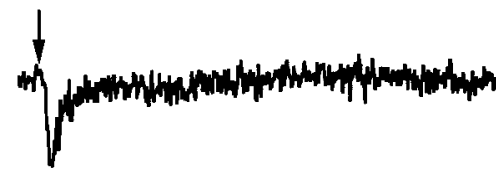

$\mathrm{Vh}=+50 \mathrm{mV}$
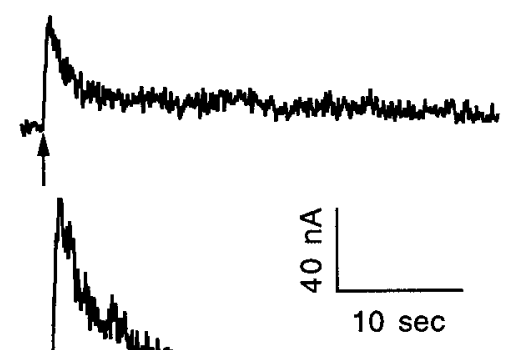

$10 \mathrm{sec}$
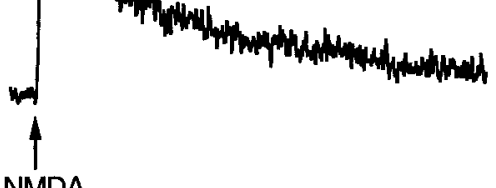

B
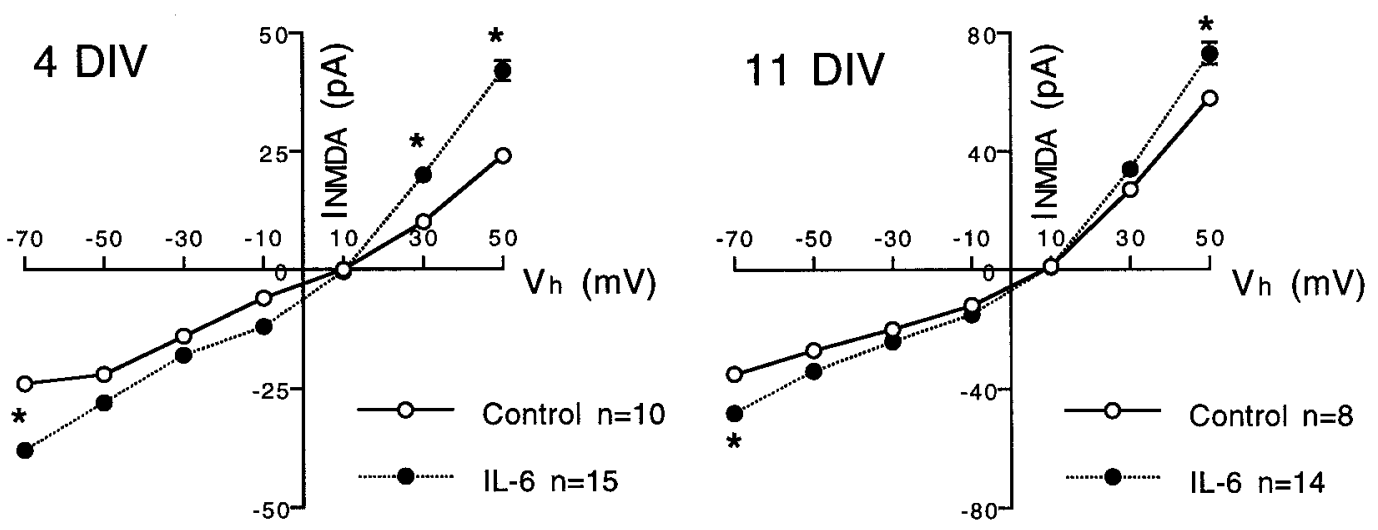

C 4 DIV

11 DIV
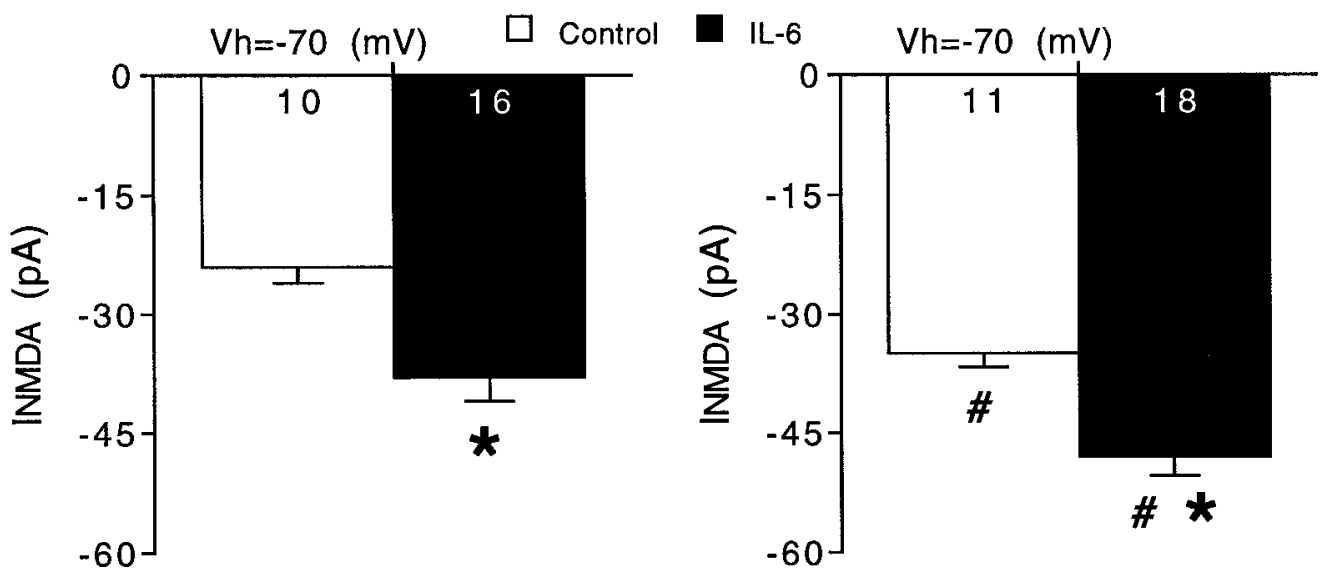

Figure 3. IL-6 enhances the current response to NMDA in cerebellar granule neurons. $A$, Representative voltage-clamp recordings of current responses evoked by brief $(1 \mathrm{sec})$ application of NMDA $(200 \mu \mathrm{M}$; applied at the arrows) in control and IL-6-treated neurons at 4 DIV at holding potentials $(V h)$ of -70 and $+50 \mathrm{mV}$. B, Current-voltage $(I-V)$ curves (mean \pm SEM) for the current response to NMDA at 4 and 11 DIV. Error bars are smaller than the symbols in most cases. $C$, Mean \pm SEM values for data collected at a holding potential of $-70 \mathrm{mV}$, the approximate resting membrane potential of granule neurons. Significant differences $(p<0.05)$ between control and IL-6-treated neurons are indicated by asterisks. Significant $(p<0.05)$ age-dependent differences within the same treatment group are indicated by number signs. Numbers in the bars represent the number of cells studied.

et al., 1995). We examined the ifenprodil sensitivity of membrane depolarizations to NMDA to determine whether receptor properties other than calcium permeability were affected by IL-6 treatment. Both control and IL-6-treated neurons exhibited sen- sitivity to ifenprodil $(0.5 \mu \mathrm{M})$ at an early developmental stage (7 DIV). However, at a later developmental stage (14 DIV), the IL-6-treated neurons were more sensitive to ifenprodil than control neurons (Fig. 4). Moreover, at this developmental stage, 

A
Control
IL-6
B
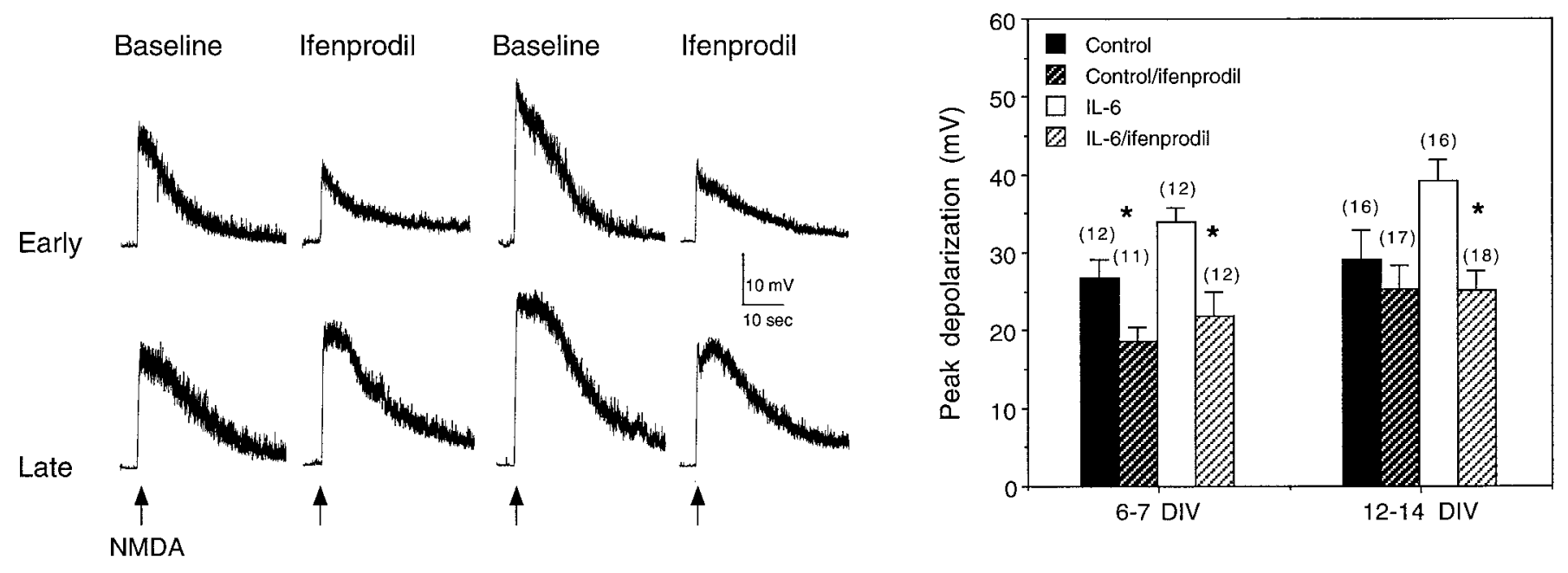

Figure 4. Effects of ifenprodil on the membrane response to NMDA in cerebellar granule neurons. $A$, Representative current-clamp recordings of membrane depolarizations evoked by brief $(1 \mathrm{sec})$ application of NMDA $(200 \mu \mathrm{M}$; applied at the arrows $)$ in control and IL-6-treated neurons at early and late developmental stages under baseline conditions and in the presence of $0.5 \mu \mathrm{M}$ ifenprodil. The recordings at the early age are from two 7 DIV control neurons in the same culture and two 7 DIV IL-6-treated neurons in the same culture. The recordings at the late age are from two 12 DIV control neurons in the same culture and two 15 DIV IL-6-treated neurons in the same culture. $B$, Mean \pm SEM values for the peak amplitude of the membrane depolarization to NMDA measured under current clamp in control and IL-6-treated neurons at two culture stages, 6-7 and 12-14 DIV, under baseline conditions and in the presence of ifenprodil $(0.5 \mu \mathrm{M})$. Control and IL-6-treated neurons showed similar sensitivity to ifenprodil at 7 DIV, whereas at 14 DIV, only the IL-6-treated neurons were sensitive to ifenprodil. Significant differences $(p<0.05)$ between control and ifenprodil-treated neurons are indicated by asterisks. Numbers in parentheses represent the number of cells studied.

ifenprodil reduced the amplitude of the depolarization to NMDA in IL-6-treated neurons to the level observed in control neurons, thus eliminating the difference between control and IL-6-treated neurons. This result suggests that at an early stage of development the relative proportion of NMDA receptors containing the NMDAR2B subunit is similar for control and IL-6-treated neurons but that at a late developmental stage the IL-6-treated neurons express a larger proportion of NMDA receptors containing the NMDAR2B subunit than control neurons.

\section{Contribution of VSCCs to the intracellular calcium signal to NMDA}

Activation of NMDA receptors increases intracellular calcium through several pathways, including (1) calcium influx through NMDA receptor channels, (2) calcium influx through VSCCs activated by the membrane depolarization to NMDA, and (3) calcium release from intracellular stores. The larger membrane depolarization to NMDA in the IL-6-treated neurons could result in greater activation of VSCCs compared with control neurons and consequently a larger contribution of calcium influx through the VSCCs in the IL-6-treated neurons. To determine whether calcium influx through VSCCs contributed to the effects of IL- 6 on the granule neurons, two types of experiments were performed: (1) we examined the effect of IL- 6 on the intracellular calcium signal and membrane depolarization to $\mathrm{K}^{+}$-stimulation, and (2) we used calcium channel blockers to determine the relative contribution of various VSCCs to the intracellular calcium signal to NMDA in control and IL-6-treated neurons.

$\mathrm{K}^{+}$-depolarization activates some of the same calcium pathway components (i.e., VSCCs and calcium release from intracellular stores) as the NMDA-induced membrane depolarization and thus enables an examination of the effects of IL- 6 on calcium pathway components, independent of NMDA receptor activation. IL-6 treatment produced little or no change in the mem- brane depolarization or intracellular calcium signal to $\mathrm{K}^{+}(150$ $\mathrm{mm} ; \mathrm{K}^{+}$substituted for $\mathrm{Na}^{+}$in physiological saline) at the early (4-5 DIV) or late (11-12 DIV) developmental stages (Fig. 5). The amplitude of the membrane depolarization to $\mathrm{K}^{+}$was larger at 11 DIV than at 4 DIV for both control and IL-6-treated neurons. However, the amplitude of the intracellular calcium signals to $\mathrm{K}^{+}$was similar for control and IL-6-treated neurons at both developmental stages.

We also compared the effects of IL-6 on the membrane depolarization and intracellular calcium signal to NMDA and $\mathrm{K}^{+}$ when a low pipette concentration of $\mathrm{K}^{+}$was used $\left(25 \mathrm{~mm} ; \mathrm{K}^{+}\right.$ substituted for $\mathrm{Na}^{+}$in physiological saline), which produces a depolarization more similar in amplitude to that evoked by NMDA. Results are summarized in Figure 6. In both control and IL-6-treated neurons, the intracellular calcium signal to NMDA was larger in amplitude than the intracellular calcium signal to 25 $\mathrm{mM} \mathrm{K}^{+}$, whereas the membrane depolarization to $25 \mathrm{mM} \mathrm{K}^{+}$was larger than the membrane depolarization to NMDA. Moreover, IL-6 treatment significantly enhanced the intracellular calcium signal and membrane depolarization to NMDA with no significant effect on the intracellular calcium signal and membrane depolarization to $25 \mathrm{~mm} \mathrm{~K} \mathrm{~K}^{+}$. These results indicate that at the developmental ages studied IL- 6 treatment does not directly influence calcium influx through VSCCs or calcium release from intracellular stores initiated by the calcium influx through VSCCs. In addition, the results demonstrate further that IL-6 selectively affects the membrane and intracellular calcium signals to NMDA at these ages.

Although IL-6 treatment had little effect on the calcium signal or membrane depolarization to $\mathrm{K}^{+}$, the population of VSCCs activated by $\mathrm{K}^{+}$depolarization may not be the same as those activated by the NMDA-induced depolarization. For example, differences in the degree of membrane depolarization produced 
A Membrane
response
to $\mathrm{KCl}$ B
Calcium
response
to $\mathrm{KCl}$
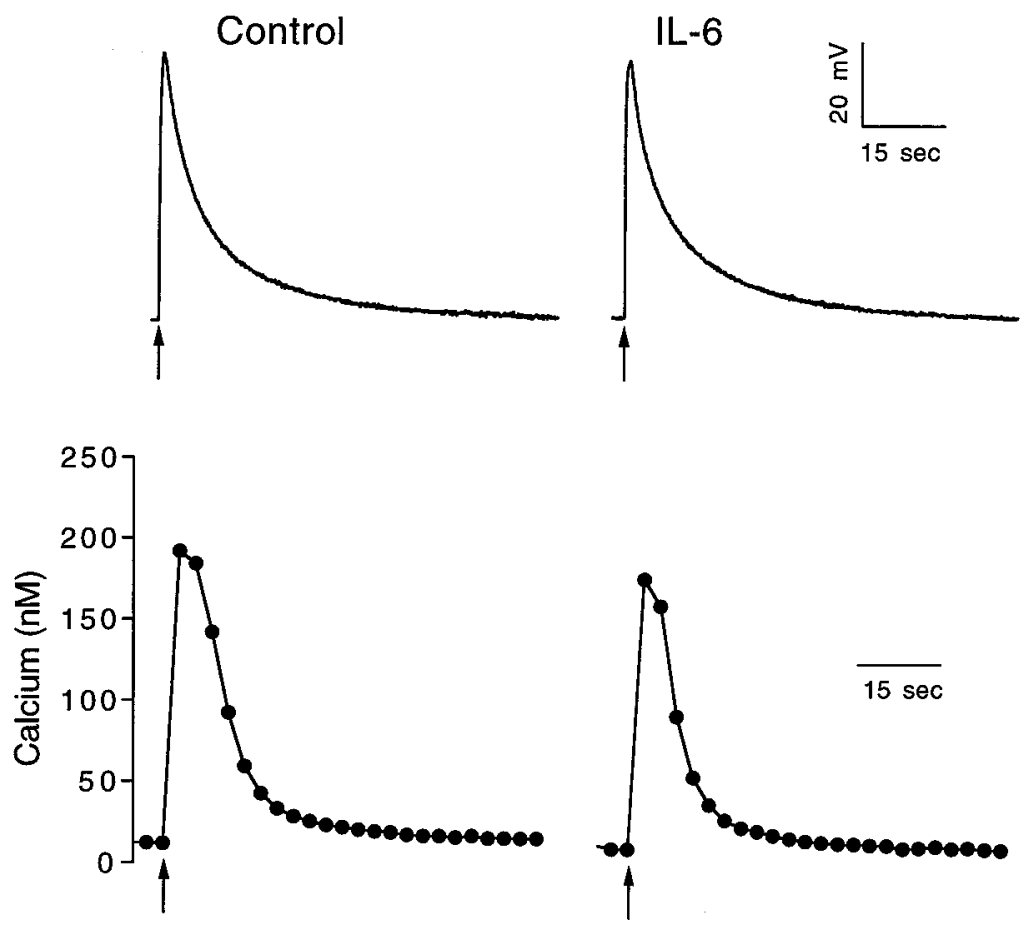
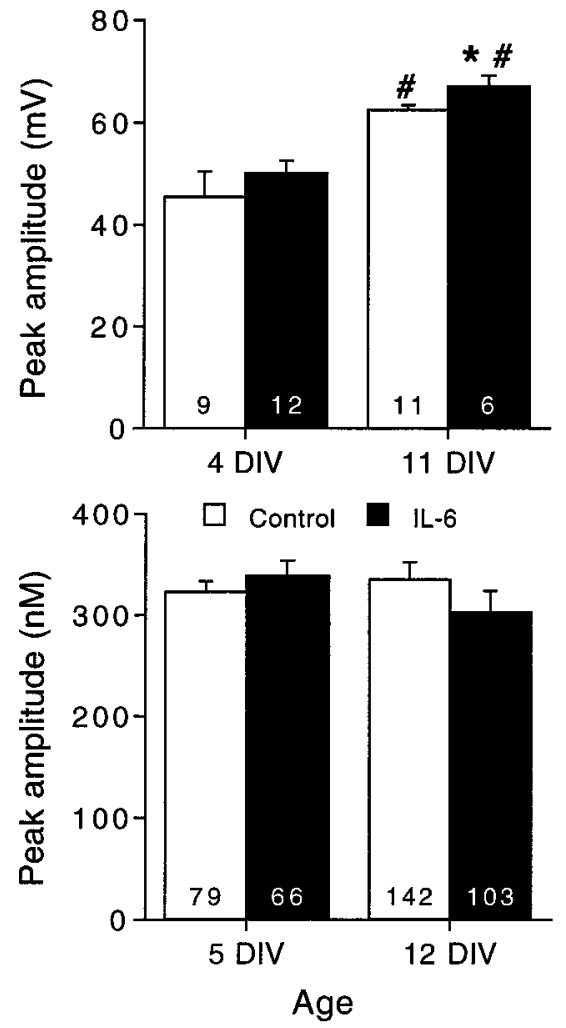

Figure 5. Effects of IL-6 on the membrane depolarization and intracellular calcium signal evoked in cerebellar granule neurons by $\mathrm{K}^{+}$depolarization. $A$, Representative current-clamp recordings of the membrane depolarization to $\mathrm{K}^{+}$in a control and IL-6-treated neuron (11 DIV) and mean \pm SEM values for the peak amplitude of the membrane depolarization to $\mathrm{K}^{+}$at two developmental stages, 4 and 11 DIV. $\mathrm{K}^{+}$was applied at the arrows from a micropipette by brief $(\sim 1 \mathrm{sec})$ microperfusion. $B$, Representative recordings of the intracellular calcium signal evoked by brief $(1 \mathrm{sec})$ application of $\mathrm{K}^{+}$(applied at the arrows) in a control and IL-6-treated neuron (12 DIV) and mean \pm SEM values for the peak amplitude of the intracellular calcium signal to $\mathrm{K}^{+}$at 5 and 12 DIV. Significant differences $(p<0.05)$ between control and IL-6-treated neurons are indicated by asterisks. Significant $(p<$ $0.05)$ age-dependent differences within the same treatment group are indicated by number signs. Numbers in the bars represent the number of cells studied.

by $\mathrm{K}^{+}$and NMDA could result in differences in the types of VSCCs activated. Other factors, such as channel clustering, could affect results as well. Therefore, in another series of experiments, we used calcium channel blockers to examine the contribution of VSCCs to the intracellular calcium signals to NMDA in control and IL-6-treated neurons. Granule neurons are known to express a variety of VSCCs, including L-, N-, and P/Q-types. We used nimodipine $(5 \mu \mathrm{M}), \omega$-conotoxin GVIA $(1 \mu \mathrm{M})$, and $\omega$-agatoxin IV-A (200 nM) to determine the effects of blocking the L-, N-, or $\mathrm{P} / \mathrm{Q}$-type VSCCs, respectively, on the intracellular calcium signals to NMDA. Only one blocker was used at a time.

All three VSCCs blockers reduced the intracellular calcium signals to NMDA in both control and IL-6-treated neurons in a developmentally regulated manner. At 5 DIV, the intracellular calcium signal to NMDA in control and IL-6-treated neurons showed a similar sensitivity to the VSCC blockers, suggesting that calcium influx through the L-, N-, and P/Q-type VSCCs contributes to the intracellular calcium signal to NMDA at this developmental stage (Fig. 7). In contrast, at 8 DIV, the IL-6-treated neurons showed a greater sensitivity to all three VSCCs blockers than control neurons. At 12 DIV, neither control nor IL-6-treated neurons were sensitive to nimodipine or $\omega$-conotoxin GVIA, whereas IL-6-treated neurons, but not control neurons, still retained some sensitivity to $\omega$-agatoxin IV-A. Together, these results show the following: (1) L-, N-, and P/Q-type VSCCs contribute to the intracellular calcium signal to NMDA in control and IL-6-treated neurons at an early developmental stage (5 DIV); (2) the contribution of VSCCs to the intracellular calcium signal to NMDA declines with development, and this decline occurs at a slower rate in the IL-6-treated neurons compared with controls; and (3) L-, N-, and P/Q-type VSCCs contribute to the enhanced intracellular calcium signal to NMDA in the IL-6treated neurons at a midstage of granule neuron development (8 DIV) in culture.

\section{IL-6 alters the dose-response relationship for the membrane and intracellular calcium signals to NMDA}

In the studies outlined above, NMDA was tested at a standard dose of $200 \mu \mathrm{M}$. In vivo, it is likely that the amplitude of the synaptic response to NMDA varies, depending on the intensity of the synaptic input. Thus, it was of interest to determine whether IL-6 altered the dose-response relationships for the membrane depolarization and intracellular calcium signal to NMDA. For these studies, NMDA concentrations of $0.02,0.2$ and $1 \mathrm{~mm}$ were tested. In both control and IL-6-treated neurons, the membrane depolarization to NMDA increased with increasing NMDA dose, whereas the intracellular calcium signal reached a maximum at 0.2 mM NMDA (Fig. 8). This discrepancy in the dose-response relationship for the membrane depolarization and intracellular calcium signal to NMDA observed in both control and IL-6treated neurons could be attributable to a contribution of calcium release from intracellular stores to the calcium signal to NMDA. 


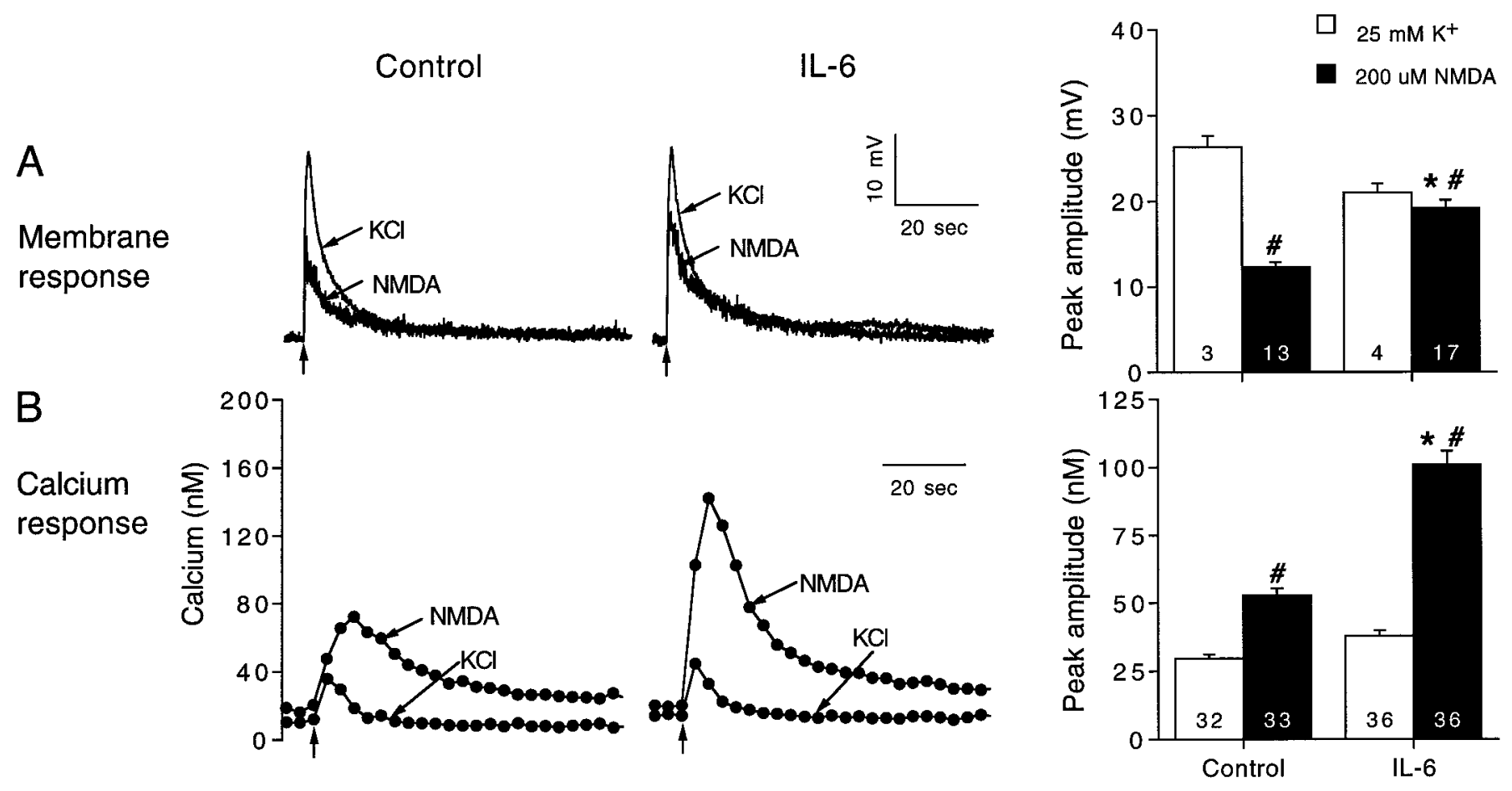

Figure 6. Comparison of the membrane depolarizations and intracellular calcium signals to NMDA and $\mathrm{K}^{+}$depolarization. $A$, Representative current-clamp recordings and mean \pm SEM values for the membrane depolarization to $200 \mu \mathrm{M}$ NMDA or $25 \mathrm{mM} \mathrm{K}^{+}$applied at the arrows by a 1 sec microperfusion pulse from a micropipette in control and IL-6-treated neurons. $B$, Representative recordings and mean \pm SEM values for the intracellular calcium signals to $200 \mu \mathrm{M}$ NMDA or $25 \mathrm{mM} \mathrm{K}^{+}$applied at the arrows by a $1 \mathrm{sec}$ microperfusion pulse from a micropipette in control and IL-6-treated neurons. Significant $(p<0.05)$ effects of IL- 6 are indicated by asterisks. Significant effects between NMDA and $\mathrm{K}^{+}$are indicated by number signs. Numbers in the bars represent the number of cells studied.

Our previous studies showed that calcium release from intracellular stores contributes to the intracellular calcium signal to NMDA in control and IL-6-treated neurons. A more parallel dose-response relationship would be expected if the intracellular calcium signal to NMDA was generated solely by calcium influx.

IL-6 treatment did not significantly alter the membrane depolarization or intracellular calcium signal to $0.02 \mathrm{mM}$ NMDA, but at the higher doses of NMDA, IL-6 significantly enhanced both the membrane depolarization and intracellular calcium signal to NMDA. This effect was more prominent for the intracellular calcium signal to NMDA than for the membrane depolarization to NMDA. These results suggest that the effects of IL-6 on the membrane depolarization and intracellular calcium signal to NMDA would have a greater effect on synaptic responses to strong stimuli and that the most prominent effect would be on the intracellular calcium signaling component of the synaptic response.

\section{IL-6 enhances NMDA-induced neurotoxicity}

Calcium plays an important role in both physiological and pathological processes. Physiologically, calcium is an important intracellular second messenger and controls a variety of neuronal functions. However, excessive intracellular calcium is associated with several neurological diseases, such as neurotoxicity caused by viral protein in HIV infection (Lipton et al., 1991). Our results showing that IL-6 enhances the intracellular calcium signal to NMDA and resting calcium levels (Qiu et al., 1995) raises the possibility that the IL-6-induced increase in intracellular calcium could influence neuronal viability. To address this question, we used an LDH assay (see Materials and Methods) to assess neurotoxicity related to NMDA receptor stimulation in control and
IL-6-treated cultures at 7 DIV. NMDA-induced LDH release increased in control and IL-6-treated neurons in a dosedependent manner (Fig. 9A). The neurotoxicity at $200 \mu \mathrm{M}$ NMDA was significantly higher in the IL-6-treated cultures compared with control cultures, whereas at 1 mM NMDA, neurotoxicity was similar in control and IL-6-treated cultures. The neurotoxicity observed at $200 \mu \mathrm{M}$ NMDA in the IL-6-treated cultures was similar to that observed at $1 \mathrm{~mm}$, suggesting that a maximal level had been reached. Interestingly, $200 \mu \mathrm{M}$ NMDA also produced a maximum response in the intracellular calcium signal to NMDA (Fig. 8), consistent with a link between the enhanced intracellular calcium caused by NMDA receptor stimulation and the IL-6-mediated toxicity.

We also measured the size of the granule neuron clusters to assess the effects of IL- 6 on cell number. The neuronal clusters are formed as part of the developmental program of granule neurons in culture (Qiu et al., 1995). Cell cluster size was smaller in the IL-6-treated cultures compared with control cultures at both culture ages studied ( 6 and 13 DIV), and the increase in cluster size with neuronal development observed in control cultures was not observed in IL-6-treated cultures (Fig. 9). Individual cell size was similar in control and IL-6-treated cultures (data not shown). These results suggest that IL-6 treatment decreases the number of granule neurons surviving in culture, perhaps because of NMDA receptor-mediated neurotoxicity.

\section{DISCUSSION}

In this study, we found that chronic IL-6 treatment during granule neuron development in culture results in enhanced membrane and current responses to NMDA, effects that parallel the en- 
L-type calcium channel blocker

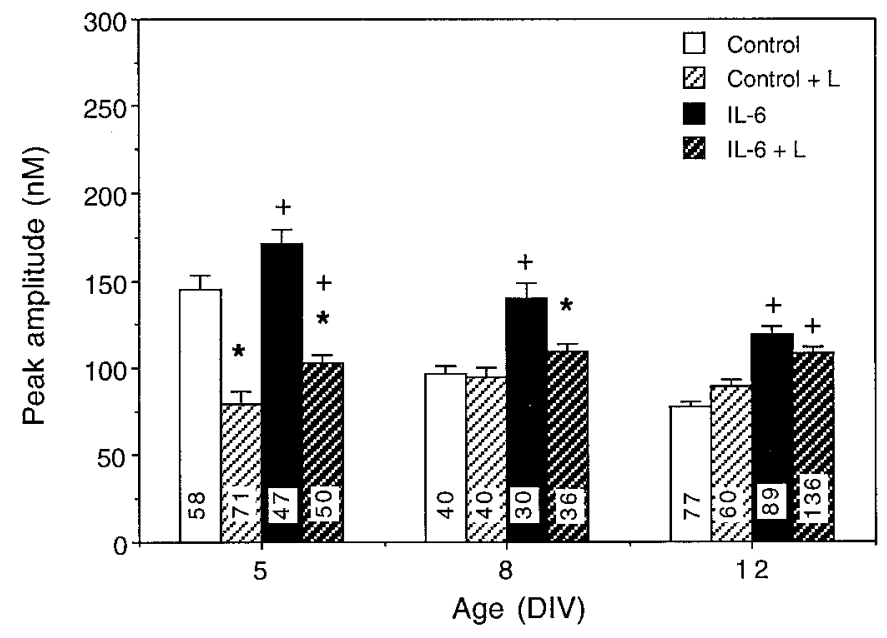

B N-type calcium channel blocker

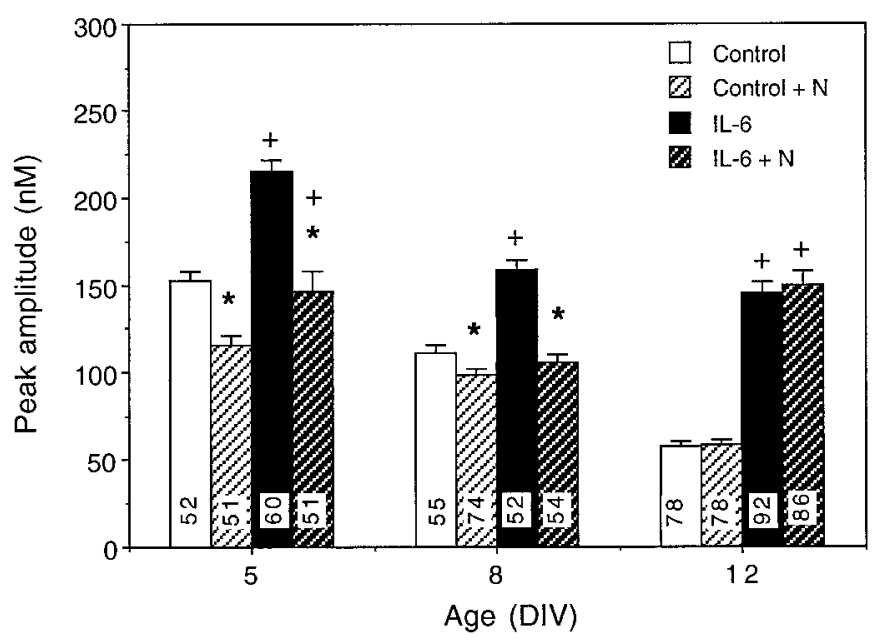

C P/Q-type calcium channel blocker

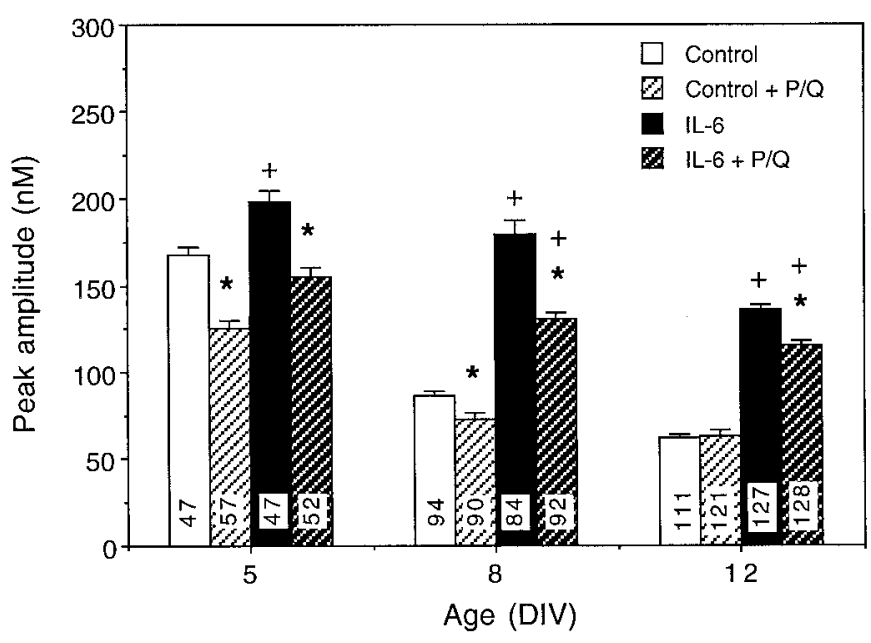

Figure 7. Contribution of VSCCs to intracellular calcium signals to NMDA. $A-C$, Effects of VSCC blockers on intracellular calcium signals to NMDA at 5, 8, and 12 DIV in control and IL-6-treated neurons. $A$, Effects of nimodipine $(5 \mu \mathrm{M})$, an L-type $(L)$ VSCC blocker. $B$, Effects of hanced intracellular calcium signal to NMDA observed in IL-6treated granule neurons (Qiu et al., 1995). Further studies showed that calcium influx through VSCCs contributes to the enhanced intracellular calcium signal to NMDA in the IL-6-treated neurons in a developmentally regulated manner. IL-6 treatment was shown also to alter ifenprodil sensitivity of the membrane depolarization to NMDA in a developmentally regulated manner. Additional studies showed that IL-6 treatment enhanced neurotoxicity involving the NMDA receptor and decreased granule neuron cluster size. Together, these in vitro results suggest that elevated levels of IL-6 in the CNS can significantly alter many aspects of neuronal physiology and development and can lead to neurotoxicity.

The mechanisms underlying the larger current response to NMDA in the IL-6-treated neurons remain to be identified. An increase in NMDA receptor number and/or a change in the receptor properties, such as channel open time, are likely to be involved. The transduction pathway mediating the effects of IL-6 on NMDA responses is unknown and may involve altered gene expression, posttranslational modification, or altered receptor turnover. The transduction pathway activated by IL-6 receptors in CNS neurons has not been identified. However, in nonneuronal cells the IL-6 transduction pathway has been shown to involve tyrosine kinases and activation of transcription factors that regulate gene expression (Taga et al., 1992; Bonni et al., 1997; Gruol and Nelson, 1997).

Several pathways contribute to the intracellular calcium signal to NMDA in CNS neurons, including calcium influx through NMDA-gated channels, calcium influx through VSCCs activated by membrane depolarization to NMDA, and calcium release from intracellular stores triggered by the increase in intracellular calcium. The larger membrane and current response to NMDA in the IL-6-treated neurons, coupled with our previous results showing a greater dependence of the calcium signal to NMDA on extracellular calcium in the IL-6-treated neurons (Qiu et al., 1995), suggests that increased calcium influx through NMDA receptors plays an important role in the enhanced calcium signal to NMDA in the IL-6-treated neurons. The parallel nature of the enhancement of IL- 6 of the current response and intracellular calcium signal to NMDA supports this interpretation, because the larger current response is likely to include greater calcium influx. The lack of effect of IL- 6 on $\mathrm{K}^{+}$depolarization is consistent with calcium influx through NMDA receptors as the primary mechanism mediating the effects of IL-6 on the intracellular calcium signal to NMDA. $\mathrm{K}^{+}$depolarization activates VSCCs, independent of NMDA receptors and, as a consequence of the calcium influx, calcium release from intracellular stores. IL-6 treatment had little or no effect on the $\mathrm{K}^{+}$-evoked intracellular calcium signal or membrane depolarization, indicating that alterations in VSCC function or calcium release from intracellular stores per se were unlikely to mediate the enhancement of IL -6 of the calcium signal to NMDA.

\section{$\leftarrow$}

$\omega$-conotoxin GVIA $(1 \mu \mathrm{M})$, an N-type $(N)$ VSCC blocker. $C$, Effects of $\omega$-agatoxin IV-A $(200 \mathrm{nM})$, a P/Q-type $(P / Q)$ VSCC blocker. Mean \pm SEM values are shown for control and IL-6-treated neurons in the presence and absence of the VSCC blocker. Significant $(p<0.05)$ effects of the calcium channel blockers on control and IL-6-treated neurons are indicated by asterisks. Significant differences $(p<0.05)$ between control and IL-6-treated neurons in the presence of the channel blocker are indicated by plus signs. Numbers in the bars represent the number of cells studied. 
Figure 8. Effects of IL-6 on membrane and intracellular calcium signals to different concentrations of NMDA. $A$, Mean \pm SEM values for the membrane depolarization to various concentrations of NMDA (applied by microperfusion as in previous figures). Results are from 11 DIV neurons. Similar results were obtained in 4 DIV neurons. $B$, Mean \pm SEM values for the peak amplitude of the intracellular calcium signal to various concentrations of NMDA (applied by microperfusion). Results are from 12 DIV neurons. Significant $(p<0.05)$ effects of IL-6 relative to control levels at the same NMDA dose are indicated by asterisks. Significant dose effects within a treatment group relative to responses at $0.02 \mathrm{mM}$ NMDA are indicated by number signs. Significant dose effects within a treatment group for responses to $1 \mathrm{~mm}$ NMDA relative to responses at $0.2 \mathrm{~mm}$ NMDA are indicated by plus signs. Numbers in the bars represent the number of cells studied.

Figure 9. Effects of IL-6 on neurotoxicity measured by $\mathrm{LDH}$ levels and cluster size. $A$, Mean \pm SEM values for different concentrations of NMDA-induced (applied by bath exchange) LDH release in control and IL-6-treated neurons. $\mathrm{LDH}$ release is expressed as a percentage of release in control cultures. Results are from 7 DIV neurons. $B$, Mean \pm SEM values for neuronal cluster size in control and IL-6-treated neurons at 6 and 13 DIV. Cell cluster size was measured as the two-dimensional area of the cluster. Significant $(p<0.05)$ effects between control and IL-6 neurons are indicated by asterisks. Significant $(p<0.05)$ dose effects within a treatment group relative to responses in the absence of NMDA are indicated by plus signs. Significant $(p<0.05)$ age-dependent increases in cluster size are indicated by number signs. Numbers in the bars indicate the number of cells studied.

Our previous studies showed that calcium release from intracellular stores contributes to the intracellular calcium signal to NMDA in control and IL-6-treated neurons and that the release component is enhanced in the IL-6-treated neurons compared with control neurons (Qiu et al., 1995). Results from the current studies indicate that the enhanced calcium release in the IL-6treated neurons is likely to result from the larger current response to NMDA and consequently greater calcium influx through NMDA receptors. A difference in the coupling ratio of calcium influx to calcium release from stores between control and IL-6treated neurons could contribute as well, and in the case of young neurons (8 DIV), calcium influx through VSCCs is a contributing factor (see below).

Although IL-6 treatment did not alter calcium influx through VSCCs, as evidenced by the lack of effect of IL- 6 on the calcium signal to $\mathrm{K}^{+}$depolarization, studies with calcium channel blockers showed that IL-6 treatment altered the contribution of calcium influx through N-, L-, and P/Q-type VSCCs to the intracellular calcium signal to NMDA. At an early developmental stage, the contribution of calcium influx through $\mathrm{N}-$, L-, and $\mathrm{P} / \mathrm{Q}$-type VSCCs to the intracellular calcium signal to NMDA was similar in control and IL-6-treated neurons. The contribution declined with development, a process that proceeded at a slower rate in the IL-6-treated neurons compared with control neurons. As a result, at a middevelopmental stage (8 DIV), N-, L-, and P/Q-type VSCCs made a larger contribution to the intracellular calcium signal to NMDA in IL-6-treated neurons than in control neurons. At a late developmental stage (12 DIV), none of these VSCCs contributed to the intracellular calcium signal to NMDA in control neurons, and only the P/Q-type VSCCs contributed to the
B

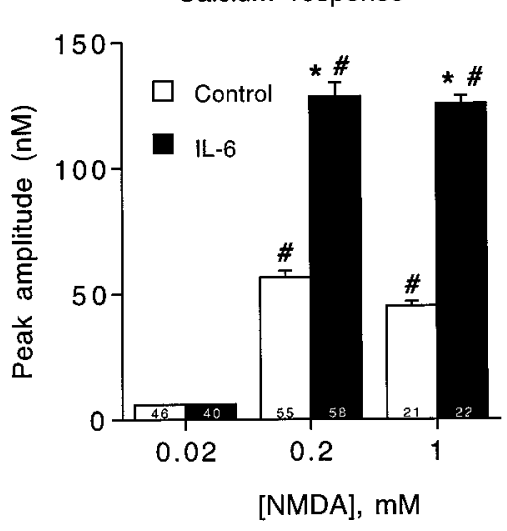

$\mathbf{B}$

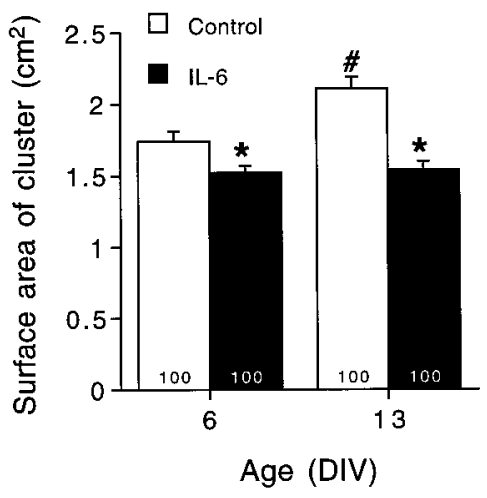

calcium signal to NMDA in the IL-6-treated neurons. Thus, although IL-6 produces an enhancement of the calcium signal to NMDA at all developmental stages, the sources of calcium differ, depending on the developmental stage. The mechanisms underlying the developmental change in the contribution of VSCCs to the calcium signal to NMDA in control and IL-6-treated neurons were not assessed in the current study but presumably involve changes in the amplitude of the membrane depolarization to NMDA, VSCCs distribution, the relative expression of the VSCC types, or the functional properties of the VSCCs. Such changes in VSCCs are known to occur during granule neuron development (Moran et al., 1991; Rossi et al., 1994; Parri and Lansman, 1996).

Studies with ifenprodil, an antagonist at NMDA receptors containing the NMDAR2B subunit, also indicate that IL-6 treatment affects the developmental program of the granule neurons. Native NMDA receptors in granule neurons in situ are formed by a combination of NMDAR1 with at least one of three NMDAR2 subunits (NMDAR2A, NMDAR2B, and NMDAR2C) (Hollmann and Heinemann, 1994; Monyer et al., 1994). NMDAR2A and NMDAR2B subunits are expressed early in development, but NMDAR2B is gradually downregulated as maturation progresses, coincident with a gradual induction of NMDAR2C (Monyer et al., 1994). Levels of NMDAR2A remain relatively stable (Akazawa et al., 1994; Monyer et al., 1994) or increase (Bessho et al., 1994; Vallano et al., 1996) during development. Ifenprodil sensitivity of granule neuron responses to NMDA declines as NMDAR2B expression is downregulated during development (Audinat et al., 1994). In the current study, control and IL-6-treated neurons showed similar sensitivity to ifenprodil at an 
early developmental stage. This sensitivity was retained in the IL-6-treated neurons, but not in control neurons, at the late developmental stage, indicating that the IL-6-treated neurons express a more immature phenotype than control neurons at the late developmental stage. These results also suggest that at the late developmental stage, IL-6-treated neurons express a larger proportion of NMDA receptors that contain the NMDAR2B than control neurons. Currents mediated by NMDA receptors containing the NMDAR2B subunit show a slower deactivation time course (and consequently a more prolonged current response) than currents mediated by NMDA receptors containing the NMDAR2A subunit (Monyer et al., 1994; Vicini et al., 1998). This property of NMDAR2B-containing receptors may play an important role in the enhanced current response to NMDA at the late developmental stage.

The enhanced membrane and current response of the IL-6treated neurons to NMDA could significantly influence excitatory synaptic transmission, neuronal function, and development. For example, activation of NMDA receptors promotes neurite outgrowth (Lipton and Kater, 1989; Collingridge and Singer, 1990), and pharmacological blockade of NMDA receptors causes an arrest in migratory movements of developing granule cells (Komuro and Rakic, 1993). Calcium influx through NMDA receptors plays a critical role in these processes. Moreover, the increased intracellular calcium signals to NMDA in the IL-6treated neurons may eventually cause neuronal death attributable to excitotoxicity and calcium overload. Excessive glutamate receptor activation, in particular NMDA receptors, has been associated with the initiation of neurodegenerative events (Choi, 1992) in several pathological states, such as HIV infection of the CNS (Lipton et al., 1991), Alzheimer's disease (Mattson et al., 1992), seizures (Rogawski, 1993), and ischemia (Simon et al., 1984). A rise in the intracellular concentration of calcium is thought to be a key step in glutamate-induced neurotoxicity (Choi, 1992; Gibbons et al., 1993). Our results show that IL-6 treatment enhances NMDA receptor-mediated neurotoxicity, perhaps because of the enhancement of the intracellular calcium signal to NMDA. A similar dose of NMDA produced the maximum intracellular calcium signal and the maximum neurotoxicity in the IL-6-treated-neurons. IL-6 levels are elevated in several disease states in which excitotoxicity is thought to be involved (Fantuzzi et al., 1995; Gitter et al., 1995; Yeung et al., 1995). Thus, IL-6 enhancement of the intracellular calcium signal elicited by NMDA receptor activation could be an important factor in the pathological process occurring in these disease states.

\section{REFERENCES}

Akazawa C, Shigemoto R, Bessho Y, Nakanishi S, Mizuno N (1994) Differential expression of five $N$-methyl-D-aspartate receptor subunit mRNAs in the cerebellum of developing and adult rats. J Comp Neurol 347:150-160

Ankarcrona M, Dypbukt JM, Bonfoco E, Zhivotovsky B, Orrenius S, Lipton SA, Nicotera P (1995) Glutamate-induced neuronal death: a succession of necrosis or apoptosis depending on mitochondrial function. Neuron 15:961-973.

Audinat E, Lambolez B, Rossier J, Crepel F (1994) Activity-dependent regulation of $N$-methyl-D-aspartate receptor subunit expression in rat cerebellar granule cells. Eur J Neurosci 6:1792-1800.

Bessho Y, Nawa H, Nakanishi S (1994) Selective up-regulation of an NMDA receptor subunit mRNA in cultured cerebellar granule cells by $\mathrm{K}^{+}$-induced depolarization and NMDA treatment. Neuron 12:87-95.

Blum-Degen D, Muller T, Kuhn W, Gerlach M, Przuntek H, Riederer P (1995) Interleukin-1 beta and interleukin-6 are elevated in the cerebrospinal fluid of Alzheimer's and de novo Parkinson's disease patients. Neurosci Lett 202:17-20.
Bonni A, Sun Y, Nadal-Vicens M, Bhatt A, Frank DA, Rozovsky I, Stahl N, Yancopoulos GD, Greenberg ME (1997) Regulation of gliogenesis in the central nervous system by the JAK-STAT signaling pathway. Science 278:477-483.

Campbell IL, Abraham CR, Masliah E, Kemper P, Inglis JD, Oldstone MB, Mucke L (1993) Neurologic disease induced in transgenic mice by cerebral overexpression of interleukin 6. Proc Natl Acad Sci USA 90:10061-10065.

Choi DW (1992) Excitotoxic cell death. J Neurobiol 23:1261-1276.

Collingridge GL, Singer W (1990) Excitatory amino acid receptors and synaptic plasticity. Trends Pharmacol 11:290-296.

Fantuzzi G, Benigni F, Sironi M, Conni M, Carelli M, Cantoni L, Shapiro L, Dinarello CA, Sipe JD, Ghezzi P (1995) Ciliary neurotrophic factor (CNTF) induces serum amyloid A, hypoglycaemia and anorexia, and potentiates IL-1-induced corticosterone and IL-6 production in mice. Cytokine 7:150-156.

Frei K, Malipiero UV, Leist TP, Zinkernagel RM, Schwab ME, Fontana A (1989) On the cellular source and function of interleukin-6 produced in the central nervous system in viral diseases. Eur J Immunol 19:689-694.

Gadient RA, Otten U (1994) Expression of interleukin-6 (IL-6) and interleukin-6 receptor (IL-6R) mRNAs in rat brain during postnatal development. Brain Res 637:10-14.

Gallo P, Laverda AM, De Rossi A, Pagni S, Del Mistro A, Cago P, Piccinno MG, Plebani A, Tavolato B, Chieco-Bianchi L (1991) Immunological markers in the cerebrospinal fluid of HIV-1-infected children. Acta Paediatr Scand 80:659-666.

Gibbons SJ, Brorson JR, Bleakman D, Chard PS, Miller RJ (1993) Calcium influx and neurodegeneration. Ann NY Acad Sci 679:22-23.

Gijbels K, Van Damme J, Proost P, Put W, Carton H, Billiau A (1990) Interleukin-6 production in the central nervous system during experimental autoimmune encephalomyelitis. Eur J Immunol 20:233-235.

Gitter BD, Cox LM, Rydel RE, May PC (1995) Amyloid beta peptide potentiates cytokine secretion by interleukin-1 beta-activated human astrocytoma cells. Proc Natl Acad Sci USA 92:10738-10741.

Grau GE, Frei K, Piguet PF, Fontana A, Heremans H, Billiau A, Vassalli P, Lambert PH (1990) Interleukin-6 production in experimental cerebral malaria: modulation by anticytokine antibodies and possible role in hypergammaglobulinemia. J Exp Med 172:1505-1508.

Gruol DL, Nelson TE (1997) Physiological and pathological roles of interleukin-6 in the central nervous system. Mol Neurobiol 15:307-339.

Gruol DL, Parsons KL (1994) Chronic exposure to alcohol during development alters the calcium currents of cultured cerebellar Purkinje neurons. Brain Res 634:283-290.

Grynkiewicz G, Poenie M, Tsien RY (1985) A new generation of $\mathrm{Ca}^{2+}$ indicators with greatly improved fluorescence properties. J Biol Chem 260:3440-3450.

Hirohata S, Miyamoto T (1990) Elevated levels of interleukin-6 in cerebrospinal fluid from patients with systemic lupus erythematosus and central nervous system involvement. Arthritis Rheum 33:644-649.

Holliday J, Parsons K, Curry J, Lee SY, Gruol DL (1995) Cerebellar granule neurons develop elevated calcium responses when treated with interleukin-6 in culture. Brain Res 673:141-148.

Hollmann M, Heinemann S (1994) Cloned glutamate receptors. Annu Rev Neurosci 17:31-108.

Hopkins SJ, Rothwell NJ (1995) Cytokines and the nervous system. I. Expression and recognition. Trends Neurosci 18:83-88.

Ip NY, Nye SH, Boulton TG, Davis S, Taga T, Li Y, Birren SJ, Yasukawa K, Kishimoto T, Anderson DJ, Stahl N, Yancopoulos GD (1992) CNTF and LIF act on neuronal cells via shared signaling pathways that involve the IL-6 signal transducing receptor component gp 130. Cell 89:1121-1132.

Johnson JE (1995) Methods for studying cell death and viability in primary neuronal cultures. In: Cell death (Schwartz LM, Osborn BA, eds), pp 242-276. San Diego: Academic.

Koh JY, Choi DW (1987) Quantitative determination of glutamatemediated cortical neuronal injury in cell culture by lactate dehydrogenase efflux assay. J Neurosci Methods 20:83-90.

Komuro H, Rakic P (1993) Modulation of neuronal migration by NMDA receptors. Science 260:95-97.

Laurenzi MA, Siden A, Persson MAA, Norkrans G, Hagberg L, Chiodi F (1990) Cerebrospinal fluid interleukin-6 activity in HIV infection and inflammatory and noninflammatory diseases of the nervous system. Clin Immunol Immunopathol 57:233-241.

Lee SC, Liu W, Dickson DW, Brosnan CF, Berman JW (1993) Cytokine 
production by human fetal microglia and astrocytes. J Immunol 150:2659-2667.

Lipton SA, Kater SB (1989) Neurotransmitter regulation of neuronal outgrowth, plasticity and survival. Trends Neurosci 12:265-270.

Lipton SA, Sucher NJ, Kaiser PK, Dreyer EB (1991) Synergistic effects of HIV coat protein and NMDA receptor-mediated neurotoxicity. Neuron 7:111-118.

Mattson MP, Cheng B, Davis D, Bryant K, Liebergurg I, Rydel RE (1992) $\beta$-amyloid peptides destabilize calcium homeostasis and render human cortical neurons vulnerable to excitotoxicity. J Neurosci 12:376-389.

McBain CJ, Mayer ML (1994) N-methyl-D-aspartic acid receptor structure and function. Physiol Rev 74:723-760.

Minami M, Kuraishi Y, Satoh M (1991) Effects of kainic acid on messenger RNA levels of IL-1 $\beta$, IL-6, TNF- $\alpha$ and LIF in the rat brain. Biochem Biophys Res Commun 176:593-598.

Monyer H, Burnashev N, Laurie DJ, Sakmann B, Seeburg PH (1994) Developmental and regional expression in the rat brain and functional properties of four NMDA receptors. Neuron 12:529-540.

Moran O, Lin F, Zegarra-Moran O, Sciancalepore M (1991) Voltagedependent calcium channels in cerebellar granule cell primary cultures. Eur Biophys J 20:157-164.

Murphy EJ, Roberts E, Horrocks LA (1993) Aluminum silicate toxicity in cell cultures. Neuroscience 55:597-605.

Netzeband JG, Parsons KL, Sweeney DD, Gruol DL (1997) Metabotropic glutamate receptor agonists alter neuronal excitability and $\mathrm{Ca}^{2+}$ levels via the phospholipase $\mathrm{C}$ transduction pathway in cultured Purkinje neurons. J Neurophysiol 78:63-75.

Parri HR, Lansman JB (1996) Multiple components of $\mathrm{Ca}^{2+}$ channel facilitation in cerebellar granule cells: expression of facilitation during development in culture. J Neurosci 16:4890-4902.

Perrella O, Carrieri PB, Guarnaccia D, Soscia M (1992) Cerebrospinal fluid cytokines in AIDS dementia complex. J Neurol 239:387-388.

Priestly T, Laughton P, Meyers J, Bourdelles B, Kerby J, Whiting PJ (1995) Pharmacological properties of recombinant human $N$-methyl-Daspartate receptors comprising NR1a/NR2A and NR1a/NR2B subunit assemblies expressed in permanently transfected mouse fibroblasts cells. Mol Pharmacol 48:841-848.

Qiu Z, Parsons KL, Gruol DL (1995) Interleukin-6 selectively enhances the intracellular calcium response to NMDA in developing CNS neurons. J Neurosci 15:6688-6699.

Rogawski MA (1993) Therapeutic potential of excitatory amino acid antagonists: channel blockers and 2,3-benzodiazepines. Trends Pharmacol 14:325-331.

Rossi P, D'Angelo E, Magistretti J, Toselli M, Taglietti V (1994) Agedependent expression of high-voltage activated calcium currents during cerebellar granule cell development in situ. Pflueg Arch Eur J Physiol 429:107-116.

Schobitz B, De Kloet ER, Sutanto W, Holsboer F (1993) Cellular localization of interleukin-6 mRNA and interleukin-6 receptor mRNA in rat brain. Eur J Neurosci 5:1426-1435.

Simon RP, Swan JH, Griffiths T, Meldrum BS (1984) Blockade of $\mathrm{N}$-methyl-D-aspartate receptors may protect against ischemic damage in the brain. Science 226:850-852.

Stahl N, Boulton TG, Farruggella T, Ip NY, Davis S, Witthuhn BA, Quelle FW, Silvennoinen O, Barbieri G, Pellegrini S (1994) Association and activation of Jak-Tyk kinases by CNTF-LIF-OSM-IL-6 beta receptor components. Science 263:92-95.

Taga T, Hibi M, Murakami M, Saito M, Yawata H, Narazaki M, Hirata Y, Sugita T, Yasukawa K, Hirano T (1992) Interleukin-6 receptor and signals. Chem Immunol 51:181-204.

Traynelis SF, Cull-Candy SG (1991) Pharmacological properties and $\mathrm{H}^{+}$sensitivity of excitatory amino acid receptor channels in rat cerebellar granule neurones. J Physiol (Lond) 433:727-763.

Tyor WR, Glass JD, Griffin JW, Becker PS, McArthur JC, Bezman L, Griffin DE (1992) Cytokine expression in the brain during the acquired immunodeficiency syndrome. Ann Neurol 31:349-360.

Vallano ML, Lambolez B, Audinat E, Rossier J (1996) Neuronal activity differentially regulates NMDA receptor subunit expression in cerebellar granule cells. J Neurosci 16:631-639.

Vicini S, Wang JF, Li JH, Zhu WJ, Wang YH, Luo JH, Wolfe BB, Grayson DR (1998) Functional and pharmacological differences between recombinant $N$-methyl-D-aspartate receptors. J Neurophysiol 79:555-556.

Waage A, Halstensen A, Shalbaby R, Brandtzaeg P, Kierulf P, Espevik T (1989) Local production of tumor necrosis factor $\alpha$, interleukin 1, and interleukin-6 in meningococcal meningitis. Relation to the inflammatory response. J Exp Med 170:1859-1867.

Williams K (1993) Ifenprodil discriminates subtypes of the $N$-methyl-Daspartate receptor: selectivity and mechanisms at recombinant heteromeric receptors. Mol Pharmacol 44:851-859.

Yeung MC, Pulliam L, Lau AS (1995) The HIV envelope protein gp120 is toxic to human brain-cell cultures through the induction of interleukin-6 and tumor necrosis factor-alpha. AIDS 9:137-143. 